\title{
Trayectoria empresarial de Pedro Aquilino López Medina
}

\section{Business trajectory of Pedro Aquilino López Medina}

\author{
Elber Berdugo $C$. \\ Candidato a Doctor en Historia de la Universidad Nacional de Colombia \\ Profesor de tiempo completo Facultad de Ciencias Administrativas y Contables de la \\ Universidad de La Salle, Colombia \\ https://orcid.org/0000-0002-9750-2618 \\ eberdugoc@gmail.com
}

Fecha de recepción: 9 de enero del 2018 Fecha de aceptación: 15 de marzo del 2018

Disponible en línea: 27 de junio del 2018

Sugerencia de citación: Berdugo C., E. (2018). Trayectoria empresarial de Pedro Aquilino López Medina. tiempo\&economía, 5(2), 209-225, doi: http://dx.doi.org/10.21789/24222704.1336

\section{RESUMEN}

La historia de Pedro A. López es un ejemplo más de muchos casos de ascenso social en Colombia de personas que no proviniendo de familias adineradas, ni de apellidos ilustres, lograron sobreponerse a múltiples dificultades económicas, políticas y sociales hasta alcanzar una posición importante en el mundo empresarial: mayor exportador de café, contratista de ferrocarriles y de transporte fluvial, banquero y accionista de varias empresas manufactureras y de servicios públicos.

Palabras clave: Empresarios colombianos, historia empresarial, desarrollo empresarial, historia económica

Códigos JEL: D72, N86, N46 


\section{ABSTRACT}

The Pedro A. Lopez story is another example of many cases of ascent in the social pyramid in Colombia, people who don't come from wealthy families or influential surnames, they were able to overcome economic, social and political difficulties and get a prominent position in the business world: Big coffee exporter, railway contractor and river transportation, banker and shareholder of several public sector and manufacturing companies.

Keywords: Colombian businessman, business story, business development, economic history

JEL Codes: D72, N86, N46 


\section{Introducción}

Una de las primeras aproximaciones académicas a la familia López, y de forma específica a Pedro A. López como empresario, se la debemos a Dávila (1986). Este escrito es de carácter exploratorio y pretende ser un complemento a la obra mencionada. El propósito consiste en describir la trayectoria del bogotano Pedro A. López - padre del dos veces presidente de la República, Alfonso López Pumarejo (1934-1938 y 1942-1945) y abuelo de otro presidente de la república, Alfonso López Michelsen (1974-1978)- quien tuvo un papel destacado en la vida económica y empresarial del país a través de la comercialización externa del café mediante su casa de comercio denominada Pedro A. López \& Compañía, la fundación de algunas instituciones financieras como el Banco López, que sirvieron de apalancamiento de sus negocios cafeteros, su incursión como accionista y gestor de empresas dedicadas a la generación de energía eléctrica en algunos departamentos, al transporte fluvial por medio de la Compañía de Navegación del Magdalena -la cual le posibilitó el traslado del café- y a la actividad manufacturera. Todas ellas le permitieron convertirse en uno de los hombres más adinerados de Colombia.

Pedro A. López representa uno de los tantos ejemplos de empresarios exitosos que proviniendo de una extracción humilde, con una instrucción básica, logró ascender en la escala social colombiana y convertirse en uno de los hombres más ricos y poderosos gracias al apoyo de una familia prestigiosa como la Samper Agudelo; a las buenas relaciones que logró establecer y consolidar con empresarios, banqueros y comerciantes nacionales y extranjeros, de quienes recibió financiación en condiciones favorables y fue representante (o lo representaron) de algunas de sus casas comerciales; a su casamiento con María del Rosario Pumarejo hija de una de las familias terratenientes y ganaderas más ricas de la Costa Atlántica quien heredó una fortuna nada despreciable que ingresó a la sociedad conyugal, a su astucia, capacidad para aprovechar oportunidades, incursionar en negocios rentables de exportación como el café, el tabaco y los cueros y de importación como los relacionados con artículos para el hogar y la agricultura, fruto de una lectura acertada del comportamiento del comercio internacional.

El ensayo, que está basado en buena parte en fuentes secundarias (aun cuando también en algunas primarias), busca llamar la atención de los investigadores sobre la vida este empresario y algunas de sus realizaciones más importantes como la casa comercial Pedro A. López \& Compañía y el Banco López, de las cuales no se ha hecho un estudio exhaustivo.

Infancia y adolescencia: Pedro A. López nació el 4 de enero de 1857 en Bogotá. Su madre fue Felisa Medina Morales, de Guayatá, "nieta de don Andrés Medina, católico de Tenza que fundara esa parroquia en 1820, antiguo alcalde de Guateque, miembro de varias asambleas cantonales, mayordomo de fábrica y presidente de la Junta Curadora de la localidad (Latorre, 1961, p. 79). Su padre, Ambrosio López Pinzón, un sastre, militante activo del Partido Liberal y fundador de la Sociedad de Artesanos de la ciudad que fue creada como respuesta a la política librecambista del Estado puesta en marcha en 1847 por el Secretario de Hacienda, Florentino González, la cual dio vía libre a la importación de vestidos y calzado, que por ser de mejor calidad y ofrecerse a precios más bajos que la de los artesanos colombianos, los colocó en una situación de desventaja, por lo que muchos de ellos quebraron.

Pedro A. López fue el segundo de cinco hijos que tuvieron sus padres. Creció en un hogar con muchas dificultades económicas, debido a que su padre Ambrosio se gastó lo pocos

tiempo\&economía

Vol. 5 N. ${ }^{\circ} 2$ - Julio - Diciembre del 2018 
recursos con que contaba apoyando a dirigentes del liberalismo quienes luego de llegar al poder, le dieron la espalda, quedando sumido en la miseria y decepcionado de la política. Así describe la situación en que se encontraba en ese momento Latorre (1961, p. 80):

Ambrosio López estaba desencantado de la política. Ella no le había acarreado sino sinsabores y pobreza. Las tesis económicas liberales desarrolladas a todo vapor desde el gobierno lo habían arruinado, a él, sastre que no podía poner a competir la torpeza de sus manos con las pulcras confecciones inglesas que entraban al país sin mayores recargos aduaneros.

Agrega Latorre (1961, pp. 80-81):

Ya no tenía amigos políticos y el país atravesaba por una de sus etapas más turbulentas. En la sastrería, acompañado de su esposa y de sus hijos Ambrosio, Pedro Aquilino, Francisco, Mercedes y Rafaela, que le fueron llegando muy graneados como suele ocurrir en los hogares pobres, el viejo conductor del liberalismo bogotano se gana trabajosamente la vida. La política la mira con una perspectiva de lejanía. La guerra del 60 de Mosquera, ya con bandera liberal, escasamente provoca su entusiasmo.

A pesar de todo, con el triunfo del partido liberal a principios de los sesentas, logró en 1862 que le dieran un cargo público como inspector de aguas de Bogotá el cual le permitió distribuir su tiempo entre los asuntos administrativos y la educación de sus hijos a quienes inició en la lectura, la escritura, les enseñó las bases de la aritmética y les transmitió algunos conocimientos primarios que él estaba en condiciones de dar.

Más adelante, Pedro A. López, gracias a que la situación económica de su padre mejoró un poco, ingresó al colegio de Luis María Cuervo en donde aprendió lo indispensable para desempeñarse como empleado en una compañía de comercio.

Su primer trabajo: Con tan sólo 15 años Pedro A. López se empleó como dependiente en la prestigiosa y acreditada casa comercial de Silvestre Samper Agudelo en donde poco a poco escaló cargos y mejoró su sueldo. Como consecuencia de la guerra de 1876 que ocasionó trastornos en la actividad económica del país y a la compañía de Silvestre Samper, este se vio abocado a cerrar el negocio y a despedirlo. Como había adquirido experiencia en asuntos mercantiles: relaciones con el público, liquidación de facturas, teneduría de libros, entre otros, decidió probar suerte el año siguiente en Cúcuta sitio muy importante del comercio exterior en el cual permaneció casi un año, sin que lograra amañarse. Aburrido de la vida que llevaba, un día cualquiera, le llegó una carta de Rafael, hijo de Silvestre Samper invitándolo a regresar a trabajar con su padre a Honda. Por ser este puerto el centro empresarial de exportaciones e importaciones más importante del país, Pedro A. López, sin pensarlo dos veces emprendió el viaje a Bogotá a pie, porque sus recursos no le alcanzaron para hacerlo montado a lomo de mula para luego dirigirse a su destino final. La descripción de la importancia económica que tuvo esta localidad en el desarrollo del país la hace Alfonso López Pumarejo:

El río era nuestro mar interior; nuestro lago de Titicaca. Todo el progreso buscaba con afán desembocar en el Magdalena como a su cauce lógico, natural. Y Honda fue por antonomasia, la ciudad del río durante muchos años. A diario llegaban a ella místeres de Manchester con telas; norteamericanos con alambre y harinas, representantes de casas francesas con vinos y champaña. Muchas firmas comerciales europeas de primera importancia mantenían allí agentes fijos. Las principales casas colombianas tenían en Honda su sede. La vida diaria en el 
puerto era una feria cotidiana de géneros y frutos de las partes más distantes del orbe. Honda era llamada "la gran escuela del trabajo. (Latorre, 1961, pp. 151-152).

Así, en 1878, Silvestre Samper lo contrató con el fin de que le ayudara a su hijo Rafael en la dirección de los importantes negocios que tenía la firma Miguel Samper e Hijos: llevar los libros principales y auxiliares, ocuparse de las facturas y aparejos de pagarés por ventas y de vez en cuando prestar apoyo en las bodegas. Pedro A. López sabía de la magnífica oportunidad que se le presentaba pues Honda era un sitio estratégico para hacer fortuna ya que tenía una ubicación geográfica privilegiada: contaba con la ventaja de su comunicación con el mar por el río Magdalena, estaba ubicada en el centro de los mercados de consumo y próxima a las zonas cafeteras, a los cultivos de cacao y a la producción de cueros que se vendían a precios altos en el exterior. La única condición adicional que puso, después de haber pactado un sueldo más alto al ofrecido fue que se le permitiera realizar algunos negocios por su cuenta si lo decidiera.

A los tres meses de trabajar Pedro A. López con Rafael, éste viaja a Ibagué a visitar a su padre y lo deja al frente de todos los negocios de compra y exportación de cueros y café e importación y venta de zarazas, harina, ropa de lino y algunos instrumentos agrícolas. En forma rápida adquiere la reputación de uno de los dependientes más serios y capaces de la localidad: “EI joven bogotano se ha hecho a fama de hombre emprendedor, tranquilo, muy puesto en orden y dueño de una visión poco común para los negocios" (Latorre, 1961, pp. 125-126).

Pedro A. López con el fin de sacarle rédito a la gran oportunidad que se le ofrecía de estar a cargo de los negocios de Silvestre Samper, se dedicó de lleno a su trabajo tomando en serio los consejos de su patrón:

La ciencia del que quiere ser rico -y eso es precisamente lo que él quiere ser-consiste en volver los días de 14 horas en lugar de 12; así es que, si por dormilón se le vuelven solamente 10 horas, le quedará un saldo de 4 horas, que durante los años que uno tiene bríos para trabajar antes de la vejez, esos saldos representan quizás los años más productivos de la vida (Latorre, 1961, p. 121).

Sus primeras incursiones en el ámbito empresarial: Debido a un viaje a Nueva York de Silvestre Samper en donde decide radicarse y constituir la firma Samper \& Bierck para huir de la guerra, Pedro A. López toma las riendas absolutas de la casa comercial ubicada en Honda. Si bien está de acuerdo con aquel en cuanto a los estragos económicos y sociales ocasionados por el conflicto armado y aunque siente una aversión por la política, culpable de que su padre no hubiera salido de la pobreza, de que él no pudiera cubrir muchas necesidades y de la primera quiebra de su jefe, se queda en Colombia.

En una de las tantas cartas remitidas a Silvestre Samper le solicita ayuda para hacer su primer negocio: importación de harina. ¿Razón? Sus deseos de formalizar relaciones amorosas con María del Rosario Pumarejo para lo cual debe tener ingresos suficientes que le permitan contar con la aceptación de su tía Josefina Pumarejo y de su Esposo, Joaquín de Mier, también para evitar las habladurías sobre el interés en la herencia de su pretendida.

Enterado Silvestre Samper de sus intenciones, le dice en una misiva que si intenta casarse debe decir adiós a su ayuda económica; escoger entre su novia y su empleo. Le recuerda,

tiempo\&economía

Vol. 5 N. 2 - Julio - Diciembre del 2018 
además "que los años de energía del hombre, que son los que van de los 20 a los 30, deben aplicarse al trabajo para adquirir capital; tampoco debe olvidar las obligaciones que le impone la pobreza de sus padres" (Latorre, 1961, p. 127). Ante tal encrucijada, decide aplazar su casamiento, esperar: "A todas las cosas les va llegando su momento".

En el negocio de la harina de maíz, no le va bien y entonces decide importar fósforos y rancho. También quiere exportar algunas frutas como plátano, pero desiste por lo complicado de su manejo. Entonces opta por traer máquinas de coser que se venden en el Tolima como pan caliente y a precios muy buenos.

A raíz de la decisión que tomó Silvestre Samper en junio de 1880, de radicarse de forma permanente en Nueva York, Pedro A. López, cree que con sus conocimientos del comercio exterior, sus magníficas relaciones comerciales y sociales y la estimación y el respeto que le profesan sus competidores y otras personas con quienes ha hecho tratos, puede establecerse por su propia cuenta y riesgo, lo cual se trunca porque se le presenta una nueva oferta: la firma Samper \& Cía. de Bogotá propiedad de Miguel, el hermano de Silvestre, le propone trabajar como empleado suyo durante el día en Honda con la libertad de realizar sus propios negocios como comisionista en la noche. Pedro A. López acepta.

En el segundo semestre de 1880 se instala en arriendo en la casa que ocuparan la familia y el negocio de Silvestre Samper en Honda. En el primer piso ubica el almacén y usa la estantería que ha comprado a un plazo de tres años a su patrón. Al finalizar el año, su negocio es próspero: vende ruanas de algodón, lana y merino con flecos que le da en consignación desde Bogotá Guillermo Uribe despachándole a la vez papel de carta y sobres. En Nueva York cuenta con créditos personales.

Desde 1881 trabaja para Dordell \& Vargas, Rafael Padilla, Hugo Biester de la Botica Alemana y le manda peinillas a Alberto Caycedo, todos radicados en Bogotá; importa cristalería de Valentín \& Frankfurter de París y vende ruanas gruesas de merino con flecos. En su almacén en Honda cuenta con el surtido más completo en barnices, munición, fósforos, palas, harina, pimienta, vino, máquinas de coser, loza, espejos, etc. Adicionalmente, viaja a Antioquia y el Tolima hasta Neiva, en donde establece nuevas relaciones comerciales y nuevos créditos. Igualmente, está al tanto de las cotizaciones de los mercados de París, Londres y Nueva York.

En los primeros años de la década de 1880 envía tabaco a Riensch \& Held de Hamburgo a pesar de la caída de las exportaciones de este producto en los primeros años de esta década comparada con el comportamiento ascendente de los precios nominales y reales desde 1845 hasta 1864; de su descenso en el resto de esta década y su estabilidad en la de los setenta que significó el principio de la decadencia tabacalera del país, debido a "la afluencia de los tabacos para envoltura de Sumatra a los mercados europeos en la segunda mitad de la década del setenta y comienzos de los años ochenta" (Ocampo, 1984, p. 219), que las situaron en su punto más bajo (en 1882, las importaciones de tabaco colombiano de Alemania sólo alcanzaron 11.980 zurrones (unas 700 toneladas) y en 1883, 22.382 zurrones ( 1.300 toneladas) que equivalían a una reversión a los niveles de 1850; la cual en cuanto valor fue más profunda (de $\$ 1.025 .685$ en $1880 / 1$, las exportaciones disminuyeron a $\$ 90.403$ en $1881 / 2$ en pesos-oro, para aumentar a \$268.782 en 1882/3 y \$395.118 en 1883/4 (Ocampo, 1984, pp. 219-221).

Desde principios de la década de 1880 se dedica también a la compra y a la exportación de grandes cantidades de café a Londres para la firma Barnes y a Estados Unidos inducido 
por las posibilidades económicas que brinda el café que en los años setenta experimentó una bonanza de precios, la cual produjo un aumento de las exportaciones del grano de 100.000 a 220.000, que según Ocampo (1989, p. 214) era considerable para la época. Para este autor: "el café dejo de ser un renglón marginal dentro de nuestro comercio exterior. Ya a fines del setenta representaba más del $20 \%$ " de nuestras ventas externas y era tan importante como el oro y la quina (Ocampo, 1989, p. 214). Y sí, es que la producción y las exportaciones de café, no obstante, la caída de su precio a comienzos de los ochentas, siguieron creciendo al pasar de 98 mil sacos de 60 kgs. Entre 1870-4 a 149 mil entre 1875-9, 221 mil entre 1880-4 a 240 mil entre 1885-9 (Ocampo, 1989, p. 216). ¿Razones?

La crisis del comercio exterior del país a principios de los ochentas y la depreciación de la plata (la base real de la circulación interna de la época) redujeron sus costos de producción en términos de oro (la unidad monetaria internacional), además del rezago de los jornales al iniciarse el periodo de la Regeneración producto de las emisiones masivas que llevaron a un aumento de la inflación. Adicionalmente, y no menos importante, otro factor que incidió en el auge cafetero fue el acceso al crédito en condiciones favorables de los hacendados al recibir préstamos por parte de las casas comerciales del exterior al $6 \%$ de interés anual con 1.5 o $2 \%$ de comisión adicional, dos años de plazo y pago en café. (Ocampo, 1989, pp. 216-217)

Durante estos años, por otra parte, Pedro A. López adquiere cantidades considerables de cueros, con el fin de aprovechar la gran demanda y buenos precios en los mercados internacionales. Así, con base en Ocampo (1989, p. 374) las exportaciones pasaron de 1.884, 8 toneladas en $1878 / 9$ a $2.618,6$ toneladas en $1879 / 80,2.961,6$ toneladas en $1880 / 1$ y a $4.342,0$ toneladas en 1887.

En 1889, después de casi diez años de trabajar como dependiente de la casa comercial Samper \& Cía., renuncia para irse con su familia al exterior. Entre las razones están: la situación política del país que cada día es más inestable y tiende a gravarse con las medidas represivas adoptadas por los gobiernos de la Regeneración contra los opositores, la prensa y los demócratas en general, las cuales las ve como una amenaza para la paz pública y los negocios mercantiles. También, el querer organizarse de forma independiente de tal manera que todo lo que gane se lo apropie él sin tener que compartir las utilidades con los Samper. Piensa que:

Si el trabajo que le dedica a la casa de los Samper lo pone al servicio de sus propios intereses en muy pocos años será rico, muy rico. Podrá rodear a su familia de comodidades, educar a sus hijos en el exterior, viajar a Europa y Estados Unidos (Latorre, 1961, p. 164).

Luego de mucha meditación viaja a Panamá en donde sus quebrantos de salud lo obligan a retornar (luego de una corta estadía) a Honda a trabajar por su cuenta:

La nueva instalación de don Pedro A., en Honda no puede ser más modesta y económica. Así hay que principiar. Se reduce a un pequeño cuarto sobre la calle, en donde tiene el escritorio de caoba, y a unos depósitos en una casa antigua, alta, sólida y aireada, que se halla situada en frente y pertenece a un señor Miguel Paz, a quien el arrendatario recordará siempre con cariño. No tiene ya el más leve reato con los Samper. Ellos, por su parte, le manifiestan que están dispuestos a ayudarle en lo que puedan. (Latorre, 1961, p. 173)

tiempo\&economía

Vol. 5 N. 2 - Julio - Diciembre del 2018 
En esta nueva etapa de su vida -principios de los noventas-, le da primacía a la exportación de café recordando las palabras que le escribiera Silvestre Samper desde Nueva York: "En este país hay mercado para toda clase de café. Desde la mugre que se vota en las mesas de escogencia hasta el de primera calidad" (Latorre, 1961, p. 174). Pero también, por la experiencia anterior exitosa que había tenido en los ochentas con el producto, el comportamiento creciente de la demanda internacional del grano y su precio y al ver que la calidad del café colombiano no tenía competencia. Igualmente, al hecho de que el $60 \%$ de la demanda mundial se concentraba en dos países (Estados Unidos con el 30\% e Inglaterra, con el 20\%) en los cuales Pedro A. López tenía en el país y en el exterior agentes hábiles y magníficos corresponsales que le permitirían movilizar en gran escala el café; contactos con empresarios vinculados al transporte por el río Magdalena quienes le brindan su apoyo. Finalmente, el estar más cerca Colombia a los Estados Unidos, que los países africanos, lo cual le otorgaba una ventaja en costos. Efectivamente, las afirmaciones de Silvestre Samper son una realidad: las exportaciones de café crecen de manera acelerada en los noventa al pasar de 246 mil sacos de $60 \mathrm{kgs}$ en 1890-4 a 491 mil en 1895-9 (Ocampo, 1989, p. 215).

En corto tiempo, los resultados comienzan a verse: Pedro A. López recibe pedidos de Londres y Nueva York para lo cual lleva a cabo compras de café en grandes volúmenes. Con los dineros que le sitúan, importa mercancías que realiza de inmediato. Ha logrado ganarse la confianza de proveedores, casas comerciales de Europa y Estados Unidos quienes le respaldan, le recomiendan o proporcionan financiación para sus operaciones a una tasa de interés del $6 \%$, más baja si se la compara con la cobrada en el país que oscilaba entre el $12 \%$ y el $15 \%$ y a plazos muy favorables (seis y nueve meses).

Por otro lado, el sistema que pone en práctica de vender en grandes cantidades, sin ganar en demasía (principio de economía de escala), le genera dinero en abundancia y le granjea las simpatías de las diferentes clases de comerciantes y compradores de la ciudad del río. “Don Pedro A. está rico; y querido y respetado por los vecinos de Honda".

En 1893, después de una larga reflexión se traslada a Bogotá pues no quería que sus hijos se quedaran sin estudiar como le pasó a él y también porque piensa que en la capital puede disfrutar más su dinero, gozar de mejores comodidades y un clima más saludable y posicionar sus negocios sin abandonar los de Honda.

En Bogotá abrió oficinas propias en la prestigiosa tercera calle Florián, frente al Banco de Colombia. Inauguró un almacén en esa calle entre el de Joaquín Páramo y el de Francisco Vargas, comerciantes famosos. Tan pronto llega a la capital toma en arriendo una casa elegante en el barrio Santa Clara, en la Calle de las Águilas, entre 7a y $8^{a}$ más allá del Chorro de las Botellas. Zuleta (1966, p. 13) la describe como "una casa enorme de Bogotá, situada en la calle de las Águilas (hoy carrera décima, calle octava) que tenía muchas alcobas, muchos patios y muchos árboles a los cuales se acostumbraron a trepar los muchachos con tanta facilidad como si hubieran dispuesto para ello un ascensor". Poco tiempo después, adquirió una bella casa localizada en la esquina de la carrera novena con calle novena. Sus negocios en Honda los dejó a cargo de Josué Tello quien se ocupó de ellos por más de 25 años. Tan bien le va que en 1895 está entre los tres principales compradores de café en la Capital de la República.

Con el advenimiento de la guerra de los Mil Días que afectó el comercio exterior y lo condujo a su parálisis; que tornó imposible al país renovar las provisiones que había conseguido ha- 
cer en los tiempos de normalidad; que llevó a que las reservas de toda índole escasearan y los productos que le permitían atender las importaciones se arrumaran en los centros de producción como sucedió con el café cuya exportación cayó de manera drástica por la imposibilidad de transportarlo; que produjo un déficit fiscal considerable por la caída de las exportaciones obligando al gobierno nacional a cubrirlo con emisiones clandestinas de billetes que condujeron a la desvalorización de la moneda nacional que alcanzó el $22.000 \%$ cuando se habían impreso mil millones de pesos, y al agravamiento de la situación económica, Pedro A. López, previendo que se venía una devaluación del peso, convirtió a monedas extranjeras todo el capital de tal forma que cuando se pusieron en marcha las medidas económicas ya tenía el dinero en poder de banqueros en el exterior. Había comprado dólares al 300\% o menos de su cambio. Con la operación no sólo había salvado su capital, sino que lo había multiplicado como resultado de la depreciación de la moneda sin proponérselo.

Su partida hacia los Estados Unidos: Pedro A. López que consideraba que había logrado amasar una fortuna por su propio esfuerzo, sus méritos personales, su sacrificio, sus privaciones en la infancia y la juventud, no estaba dispuesto a perderla, menos aún ahora que tenía varios hijos, dejarla expuesta a contingencias y riesgos que él no había buscado, que eran producto exclusivo de la ligereza ajena:

Del gobierno conservador empeñado en mantener al país bajo su duro puño exclusivista. De los guerreristas liberales que habían lanzado al partido a la insurrección sin medir, en su rabiosa, aunque justa protesta, la dimensión total de su acción. La conflagración civil azotaba las regiones en donde Pedro A., había desarrollado sus negocios desde muchos meses antes. En purificación, Neiva, Garzón, Ibagué, Honda, los impactos de la guerra eran tremendos. Don Pedro A., se había visto forzado a liquidar sus negocios en esas regiones. Y si tenía ya puesto su capital a salvo del caos, quería colocar ahora a su familia al margen de los peligros de la anarquía (Latorre, 1961, p. 289).

En 1901 tomó la decisión -acelerada- de radicarse en Nueva York con su familia, porque su hijo Alfonso estaba entregado a la política y se había mezclado en asuntos clandestinos. El recuerdo de su padre que lo había perdido todo por estar inmerso en la política, lo atormentaba y no quería que se repitiera la historia. Por eso lo pone a salvo enviándolo a estudiar a Londres en los primeros días de 1901. El resto de la familia emprende viaje al exterior con 16 bultos de equipaje entre los cuales lleva una gran cantidad de oro en polvo y en barras. Ya está en alta mar, irrevocablemente a salvo; en aguas del Caribe, rumbo a Puerto Rico y su hijo Alfonso en Londres en donde el sastre le diseñará nuevos vestidos y el dentista le hará un arreglo de sus dientes.

Estando Pedro A. López en Estados Unidos, centro de sus principales operaciones empresariales de importación y exportación y lugar de residencia durante siete años, le confió a Alfonso López, después de cursar estudios en el Brighton College y haberse capacitado en comercio en la Packard School, con tan solo 18 años de edad, la administración de la firma Pedro A. López \& Cía. ubicada en Bogotá, desde donde se controlaban los negocios ubicados en el resto del país y los que tenía con otros países, los cuales estaban atendidos por el banquero Ernesto Michelsen. Durante 12 años se hizo cargo de ellos de manera exitosa logrando que la firma obtuviera un inmenso prestigio. Por desacuerdos con su padre y sus hermanos, renunció a la dirección de la empresa y se distanció del primero durante varios años. Alfonso López alude a

tiempo\&economía

Vol. 5 N. ${ }^{\circ} 2$ - Julio - Diciembre del 2018 
su estadía en la compañía y a los motivos de su dimisión, en una carta del 27 de diciembre de 1919 dirigida al señor Alfred Meyer, Gerente General del Banco Mercantil de las Américas en Nueva York:

Estas circunstancias me recuerdan a cada paso, las que determinaron mi separación de la Casa de los señores Pedro A. López \& Cía., de la cual entraron a ser socios mis hermanos, con una participación en las utilidades igual a la mía, y sin que hasta agosto de 1914 tuvieran otro oficio que pasear por Europa y Estados Unidos. Cuando accidentalmente se encontraban en Bogotá, se ocupaban en averiguar a qué horas entraba o salía yo de la oficina y qué dejaba de hacer. Así aconteció que una mañana peleé con uno de ellos porque llegué tarde a mi escritorio y no había otra persona que tradujera varios cables recibidos en clave particular; después de que me retiré de la firma, dejándola muy delante de sus competidores en el país y bien conectada con banqueros de primer orden en New York, Londres y París, resultó que yo no había hecho ninguna gracia en celebrar los arreglos que sirvieron de base a la expansión prodigiosa de los negocios de la casa de mi padre; y resultó también que mis esfuerzos dizque habían sido compensados con exceso, porque había mecanógrafos y contabilistas y corresponsales que trabajaban más que yo. Mis hermanos se creyeron siempre capaces de reemplazarme sin dificultad, aun en asuntos que ellos ignoraban por completo y que yo llevaba doce o quince años de estar estudiando; y mi padre, que no ahorró jamás gasto ni esfuerzo de ninguna naturaleza en educarme y que en todo tiempo y lugar trató de elevarme a las mayores alturas, cuando ya vio a Pedro A. López \& Cía. con sus banderas clavadas en la calle de Florián como ciertos banqueros tienen elevadas las suyas en Broad Street, principió a caer bajo la influencia de los celos..., cual si Alfonso fuera una persona distinta del hijo mayor de Pedro A. López (Zuleta, 1966, p. 21).

Luego de su retiro de Pedro A. López \& Cía., sus hermanos se encargaron de manejar la casa hasta el colapso sufrido en 1923, año en que Pedro A. López se había trasladado a su finca La Mana.

Participación de Pedro A. López en la creación de otras empresas: Además de las actividades relacionadas con el comercio exterior, principalmente con la exportación de café, Pedro A. López incursionó en otros negocios. Su nieto Alfonso López Michelsen hace una relación de algunos de ellos:

Pedro A. López encarnaba el éxito económico, conseguido con honestidad, tesón indiscutible y reconocimiento unánime en un medio inclinado a exaltar el ascenso en la vida empresarial. Llegó a exportar el 70\% del café que producía Colombia, fundó bancos, empresas navieras en el río Magdalena [Compañía de Navegación del Magdalena] y, también, en el trayecto entre nuestra Costa Norte y los puertos de la Costa Este de los Estados Unidos; construyó ferrocarriles [Ambalema-lbagué y Tolima-Huila-Caquetá] cuando todavía en los países industrializados empresas de tanto calibre las emprendían los particulares. Fue industrial de textiles [fábrica de paños La Magdalena], de la elaboración de harina de trigo [fundó un molino de trigo en Honda], de los servicios públicos de energía eléctrica (estableció plantas de generación en Honda y Líbano) y de transporte amén de otras muchas actividades que me cansaría de enumerar (López, 2009, pp. 26-27).

Adicionalmente, estableció trilladoras en los municipios de Girardot, Líbano, Circasia, Medellín y La Palma para la transformación del café, negocio muy rentable. Fue socio fundador 
de la fábrica de calzado La Corona. E inició los trabajos de construcción del acueducto y el alcantarillado de la ciudad de Ibagué.

Inversiones en la banca: Mención especial ameritan sus inversiones en la fundación de establecimientos bancarios como:

El Banco López. Esta entidad que se constituyó en poco tiempo en la institución financiera más destacada del país, colocando líneas de crédito concedidas por bancos estadounidenses y europeos, lo fundó en Bogotá Pedro A. López el 8 de enero de 1919 en compañía de destacados empresarios colombianos entre los cuales estaban los Salazar, los Robledo, Holguín, Koppel, Samper, Sáenz, Cuervo, Pedro A. López \& Cía., y algunos familiares, dedicados a distintas actividades económicas como el comercio, la agricultura y la banca.

El capital suscrito fue de 500.000 pesos oro moneda inglesa (100.000 libras esterlinas) representadas y divididas en 5.000 acciones de 100 pesos oro, es decir 20 libras esterlinas, de las cuales 1.000 eran propiedad de Pedro A. López; 1.250 pertenecían a la sociedad Pedro A. López \& Cía., 1.000 las suscribieron los López Pumarejo (AGN, Notaría segunda, 08-01-1919). Al sumar la participación de Pedro A. López, con la de sus socios y la de sus familiares, se colige que tenía un control del banco con un porcentaje del 65\%. Posteriormente, el capital del banco se aumentó hasta alcanzar la suma de 4.000 .000 de pesos moneda inglesa ( 800.000 libras esterlinas) en 1921.

El banco se creó principalmente para financiar la actividad cafetera de Pedro A. López \& Cía. y de otros empresarios partícipes del negocio del café en su época de auge. Child y Arango $(1988$, p. 93) se refieren a aquel y al incremento del precio del grano de la manera siguiente:

El Banco López surge en la cresta del auge cafetero 1915-1919 cuando las exportaciones de café empiezan a subir vertiginosamente a la par de los precios. Los precios del grano se mantuvieron entre octubre de 1919 y 20 de marzo de 1920 a $\$ 65$ arroba (el cambio estaba casi a la par con el dólar).

La quiebra del Banco López. El tiempo de duración que se fijó al Banco fueron 50 años, pero únicamente duró cuatro años y medios como consecuencia del descenso del precio del café y por ende de las exportaciones (luego de un auge sostenido por varios años) debido a la crisis mundial de 1920, que lo afectaron a él y a muchos exportadores, llevándolos a la quiebra y a algunos que los habían financiado. Al respecto Ocampo (1989, p. 229) anota lo siguiente:

La mayoría de las principales casas comisionistas del país quebraron durante la crisis de 1920. El fin de la primera guerra mundial había generado una ola de especulaciones sin precedentes en los mercados de materias primas. En el caso del café, la oleada se agravó a raíz de la helada brasileña de 1918. Las cotizaciones del café colombiano se elevaron de 14 centavos de dólar por libra a mediados de 1918 a más de 30 centavos un año más tarde. Los altos precios se mantuvieron hasta mediados de 1920, pero la crisis mundial que se inició entonces arrasó las cotizaciones del grano, que ya para fines de dicho año habían retornado a los niveles anteriores a la helada.

Agrega el autor que:

tiempo\&economía

Vol. 5 N. 2 - Julio - Diciembre del 2018 
Esta crisis generó pérdidas cuantiosas a las firmas exportadoras, que habían adquirido grandes volúmenes del grano durante los meses de bonanza, que se encontraban todavía en tránsito a mediados de 1920. Para hacer las cosas aún peores, una sequía había reducido el caudal del río Magdalena complicando enormemente la remisión de las mercancías. Para fines del año, muchas firmas habían quebrado. (Ocampo, 1989, p. 229)

El primer tropiezo lo sufrió el banco en 1920 cuando en diciembre el precio cayó en forma acelerada a menos de su tercera parte del observado unos meses antes (\$2,10 la arroba). Comerciantes que habían comprado café a $\$ 6,50$ la arroba, tuvieron que venderlo a $\$ 2,10$ la arroba, arrojándoles una pérdida por arroba de $\$ 4,40$ quedando en la ruina. ${ }^{1}$

Entre los que se quebraron en esa oportunidad como consecuencia del derrumbe del precio del café estuvo el Banco Sucre, perteneciente al grupo antioqueño Vásquez \& Correa. El Banco López pudo sortear la situación (que se expresó en un retiro intempestivo de los depósitos por parte de los clientes) gracias a la mano que le tendieron varios bancos extranjeros quienes le proporcionaron un préstamo de \$475.000 así: The Comercial Bank o Spanish América Limited \$250.000; el Banco Mercantil Americano (cuyo gerente de la sucursal en Colombia era su hijo Alfonso) \$150.000; The London and River Plate Bank, \$65.000; The National City Bank, $\$ 10.000$. El plazo para el pago de la deuda fue: la mitad a seis meses y la otra mitad a un año (AGN, Notaría segunda, escritura 2.517, 01-12-1920).

El segundo tropiezo que no pudo sortear el banco y que condujeron a tomar la decisión a sus propietarios de cerrarlo en forma definitiva, fue el desplome del principal receptor de dinero del banco, la firma comercial Pedro A. López \& Cía. que se vio forzada a su quiebra por la caída del precio del café y al fracaso de sus actividades especulativas en la construcción de ferrocarriles y la inversión en bienes inmuebles. Randall $(2007$, p. 33) sintetiza estos dos factores:

Uno fue el colapso del precio del café en el mercado internacional. Las pérdidas fueron inmensas para los bancos que habían invertido en cosechas de café con objeto de exportarlo a mayor precio. El otro fue la especulación con tierras en diversas áreas como Carare, Guayabito y Flores, en que la compañía se había envuelto. Estaban en juego, cerca de ciento cincuenta mil hectáreas. Las compañías ferroviarias británicas y americanas habían expresado su deseo de poseer derechos ferroviarios en estas áreas y la compañía López buscaba que se declarara que las tierras eran privadas y por lo tanto susceptibles de ser vendidas en lugar de pertenecer al dominio nacional. La gestión de la compañía no tuvo éxito y los fondos depositados para la construcción de las vías férreas fueron congelados.

La versión de uno de los nietos de Pedro A. López coincide con la de Randall. Según López (2009: 103) la quiebra de la casa se debió a:

Toda clase de operaciones temerarias, yo diría alocadas...La construcción de dos ferrocarriles financiados con letras de cambio a noventas días vista: El Tolima-Huila-Caquetá y el lbagué-Ambalema. Además se habían adquirido, por compra al señor Pedro Ignacio Uribe, unos terrenos supuestamente petrolíferos en la región del Carare, por la suma de quinientos mil dólares de la época, y, no obstante haberse cerciorado de la legitimidad de los títulos de propiedad privada que amparaban los terrenos de Carare, Guayabito y Flórez, adjudicados durante la administración Santander a un tal Juan Florentino Sánchez, el asunto se había vuelto

1 Para una descripción detallada de la crisis cafetera y sus secuelas ver Acosta (2003, pp. 273-307). 
litigioso por obra de las compañías americanas e inglesas que aspiraban a obtener concesiones del Estado colombiano en la misma región en donde se habían descubierto los yacimientos de Barrancabermeja, Infantas y la Cira.

Afirma López (2009, p. 23):

El Gobierno Nacional, antes de que Pedro A. López \& Compañía formalizara el negocio de compra, por boca del Ministro Jesús del Corral, había expedido un certificado a Pedro A. López \& Compañía, declarando que tales terrenos no eran baldíos y habían salido del patrimonio nacional con anterioridad al 28 de octubre de 1873 (Código Fiscal de la Federación), cuando las adjudicaciones de tierra comprendían el petróleo y el subsuelo, hasta entonces desconocido. No obstante, todas esas precauciones y el concepto de los abogados más eminentes de la época, consultados para el efecto, floreció en la Provincia de Vélez una epidemia de falsificaciones e incendios de notarías que pusieron en tela de juicio la validez de la adjudicación de las 150.000 hectáreas a Juan Florentino Sánchez durante la administración Santander.

En conclusión, en palabras de López (2009, p. 23):

Quebró la firma exportadora de café, como sucede todavía cuando se presentan desplomes de precios en el mercado de Nueva York, y quebró entre otras razones, por la congelación de fondos en la construcción de los dos ferrocarriles y el carácter súbitamente litigioso de los terrenos del Carare, que se hubieran podido vender con ventaja a cualquiera de las compañías petroleras interesadas en el país, si no hubiera estado sub judice la autenticidad del título de dominio. Con sólo haber vendido por un millón de dólares aquel activo se hubiera salvado el resto del patrimonio de la firma, mediante la obtención de plazos para garantizar el pago de otros pasivos.

Sostienen Child y Arango $(1988,97)$ que los accionistas del banco antes de su cierre definitivo adelantaban gestiones con el propósito de lograr un préstamo con el Lazard Fréres de París-Londres por $\$ 900.000$ para refinanciar la deuda del ferrocarril Tolima-Huila-Caquetá que el departamento del Tolima no había podido cancelarle a Pedro A. López y que ahora debía cubrir el Gobierno Nacional que lo había adquirido.

Según los autores:

El empréstito inglés sería intermediado por el grupo Pedro A. López con la garantía general de la nación, sin comprometer específicamente ningún bien ni renta nacional, y con la condición de contrapartida de que el Gobierno de Colombia invertiría una suma no inferior al millón de libras del empréstito. De la suma saldría la parte para la refinanciación de la deuda y para otras obras públicas en proyecto, como el ferrocarril del Atlántico, Bogotá-BarranquiIla, sobre el cual ya había, inclusive propuestas norteamericanas. (Child y Arango, 1988, p. 97)

De acuerdo con Child y Arango (1988), los inconvenientes insalvables que se presentaron dieron al traste con las iniciativas emprendidas para rescatar al banco:

Las obras deberían ser aceptadas por la casa constructora de ingenieros Pearson \& Sons, lo cual violaba evidentemente, las disposiciones de la Ley 102 de 1922, lo mismo que la compra en subasta pública de los materiales en Londres. El Presidente Pedro Nel Ospina, no quería "créditos atados". (Child y Arango, 1988, p. 97) 
Aunque las condiciones del crédito eran favorables, para Pedro A. López, el gobierno hizo caso omiso a la petición del banquero y en víspera de la quiebra el Presidente de la República ${ }^{2}$ ordenó el retiro de los fondos oficiales de la Tesorería del Banco López y no movería un dedo para que se aprobara el préstamo.

¿Cuál era la situación financiera del Banco López antes de suspender los pagos el 15 de julio de 1923? El balance presentado al público por su gerente Eduardo López Pumarejo ese día reflejaba que el

Banco sólo disponía de en caja de 180.000 pesos para cancelar un total de deudas exigibles (depósitos en cuenta corriente, en caja de ahorros, y en cuentas corrientes de exportación) de cerca de 2 millones de pesos, o sea una iliquidez total de 10:1. La obligación por cobrar, deuda del Ferrocarril del Tolima por $\$ 900$ mil, tenía apenas valor jurídico de papel, pero no valor de cambio inmediato. (Child y Arango, 1988, p. 97)

Child y Arango (1988, p. 99) sostienen que la publicación del balance fue fatal:

La cola de viudas que siempre son las más sensibles a los rumores, se formó desde el alba en las puertas del banco... Los respaldos que exhibía el banco sobre hipotecas no contaban para nada en estos momentos de demanda caliente de dinero.

De nada valieron las inversiones que tenía el Banco López en otros bancos que ascendían a $\$ 572.000$, ni el total de activos que sumaban $\$ 2.200 .000$, comparado con los $\$ 180.000$ disponibles en caja para atender los retiros masivos de dinero que ante la falta de liquidez en ese momento no pudo atender conduciéndolo el 17 de julio a suspender los pagos y por ende a su cierre.

Child y Arango (1988 p. 98), consideran que, de todas formas, hasta con el apoyo del Ejecutivo, el Banco López en menos de un año hubiera cerrado sus puertas:

Es posible que, si el gobierno del General Pedro Nel Ospina no retira los fondos que la Tesorería tenía en el Banco López, y si oportunamente aprueba el empréstito Lazard Fréres, el banco hubiera podido sostenerse unos seis meses más. Pero no el Grupo López. La Misión Kemmerer, ya les había cerrado el camino a los bancos de comerciantes.

El Banco de Vélez. Se constituyó el 27 de agosto de 1919 como sociedad anónima en esta ciudad con un capital de 20.000 pesos oro moneda inglesa (4.000 libras esterlinas) con una participación de Pedro A. López del $40 \%$ de las acciones y de su hijo Pedro N. del 20\%. Como objeto social se estipula:

Ejecutar todas las operaciones y prestar todos los servicios de los bancos comerciales de giro y descuento como los que existen actualmente en el país, y que permiten las disposiciones legales sobre compañías anónimas, sociedades de crédito y demás establecimientos de esta clase, cuyos principales servicios y operaciones son los siguientes: descontar obligaciones, pagarés y giros; hacer préstamos de dinero; comprar y vender giros sobre el exterior,

2 Ocampo (1989, pp. 229-230) al referirse al cierre del banco dice: "A mediados de 1923 desaparecería, en medio de un episodio confuso, que algunos analistas han asociado con acciones del gobierno de Pedro Nel Ospina dirigidas a crear una crisis financiera propicia para la fundación del Banco de la República". 
abrir créditos flotantes en cuenta corriente; recibir fondos en depósito a plazo o a la orden o para pagos a la vista en cuenta corriente; comprar y vender bienes muebles e inmuebles (AGN, Notaría segunda, escritura 1.605, 27-08-1919).

Este banco se creó con el fin de apalancar los negocios cafeteros que tenía Pedro A. López en el oriente. La duración prevista fue de 50 años, sin embargo, apenas duró cinco viéndose obligado a fusionarse con el Banco de San Gil debido al decaimiento de la economía de la ciudad.

Otras instituciones financieras en la que participó como socio fundador Pedro A. López fue el Banco Central Hipotecario de Colombia, Banco Republicano de Medellín, Banco Social del Tolima, Banco Social del Huila cuyas inversiones en los tres últimos ascendieron a $\$ 572.000$ y las realizó a través del Banco López. Al igual que los otros bancos, su objetivo fue el de apoyar financieramente el negocio del café. Debido a que no se encontró información para reconstruir su historia, apenas se mencionan como uno de los aportes de capital que llevó a cabo en ese proceso de expansión de su actividad empresarial.

El edificio Pedro A. López. Algunos empresarios colombianos contribuyeron a la modernización del país y de Bogotá en particular no sólo con su actividad económica sino también con sus gustos personales refinados, aportando a la transformación arquitectónica de la ciudad. Este fue el caso de Pedro A. López con el edificio que lleva su nombre.

Un poco de historia. La idea de construir un edificio que sirviera de centro de operaciones de la actividad financiera del empresario surgió luego de apreciar en su visita a Nueva York, el estilo art déco de sus edificios. Más tarde, cuando regresó a Colombia en 1908 y una vez la prosperidad de su negocio se lo posibilitó, acometió la construcción de lo que se iría a constituir en un símbolo del corazón bancario.

Pedro A. López contrató al arquitecto norteamericano Robert Farrington para que hiciera el diseño. La construcción la encargó a los hermanos Fred y Harold Ley, quienes posteriormente construirían la Torre Chrysler en Nueva York, entre 1928 y 1930. La obra tardó cuatro años en estar lista: 1919-1923. Se erigió el edificio en un terreno de 4.300 varas en "el barrio la Catedral, junto al puente de San Francisco, esquina del antiguo parque de la artillería" (hoy en día Avenida Jiménez, entre las carreras $8^{\mathrm{a}}$ y $7^{\mathrm{a}}$ ).

En la construcción del edificio Pedro A. López, invirtió una gran suma de dinero, sin medirse en gastos. Quería lo mejor de lo mejor.

Gastó a manos llenas para proporcionar el mayor nivel de lujo a su establecimiento comercial. Se mandaron a pedir materiales de toda Europa y de Estados Unidos, sin tener reparos en los altos costos que esto implicaba: las columnas fueron traídas desde Italia; el reloj principal desde Suiza y los modelos de puertas y ventanas se fabricaron en los Estados Unidos. De igual manera, diversos elementos decorativos como las barandas de bronce, el mármol y las cortinas fueron importados para dar el mayor nivel de esplendor al que hasta ese entonces fuera la construcción más grande jamás realizada en Bogotá (Edificio Pedro A. López: inicios del modernismo en la arquitectura colombiana, 2015).

En su época, algunos sectores de la sociedad bogotana elogiaron su estilo moderno, que imitaba el del art déco de la primera escuela de Chicago; admiraban las innovaciones técnicas

tiempo\&economía

Vol. 5 N. 2 - Julio - Diciembre del 2018 
que la construcción de la edificación trajo al país como la estructura de acero revestida en cemento y la introducción del primer ascensor en un edificio colombiano, entre otros avances.

A lo largo de la construcción del edificio hubo muchos inconvenientes: dificultades técnicas, falta de mano de obra calificada; problemas relacionados con la consecución de los objetos decorativos de lujo importados de todos los rincones del mundo; demoras en las entregas de materiales; altos costos del transporte, los cuales produjeron retrasos en la obra, elevaron los costos en un $150 \%$. Así, como consecuencia del aumento de éstos y de la crisis que sufrió la economía cafetera colombiana a principios de la década de los veinte en Colombia, que afectó a Pedro A López y lo condujo a la bancarrota, éste no pudo disfrutar de la belleza arquitectónica, viéndose obligado a desprenderse de él vendiéndolo al Banco de la República para poder cubrir parte de las deudas contraídas (Edificio Pedro A. López: inicios del modernismo en la arquitectura colombiana, 2015).

El edificio estuvo en manos del Banco de la República hasta 1958. A lo largo de treinta y cinco años, lo utilizó como sede de operaciones, de reuniones de la junta directiva y de bóveda. Parte de sus instalaciones se emplearon para desarrollar actividades culturales y guardar documentos históricos. Debido a las limitaciones de espacio, el edificio se vendió al Banco Cafetero. Posteriormente, el edificio se le cedió al Ministerio de Agricultura y Desarrollo Rural, en donde actualmente funciona.

Desde su adquisición por el Banco de la República en 1924, el edificio Pedro A. López sufrió dos grandes intervenciones:

La primera fue en 1932, cuando se le añadió un piso a la planta cuadrada original; la segunda tuvo lugar entre 1944 y 1948, cuando la estructura original, que constaba de dos masas separadas por un patio donde se encontraba una estatua de Simón Bolívar del artista Mariano Benlliure Gil, cambió radicalmente al ser reemplazado el patio por un vestíbulo central, que se conserva aún. En 1984, por cuenta del Decreto 2390 del 28 de septiembre de 1984, el Edificio Pedro A. López fue declarado patrimonio material de la ciudad de Bogotá, por lo cual no ha sufrido más modificaciones desde entonces (Edificio Pedro A. López: inicios del modernismo en la arquitectura colombiana, 2015).

Pedro A. López, además de la actividad empresarial que desarrolló durante buena parte de su existencia (1904-1924), incursionó en la política, pese haber renegado varias veces de ella y criticado a su hijo Alfonso por tomar el camino de su padre Ambrosio. Así, fue Concejal de Bogotá por el Partido Liberal entre 1917 y 1919 y Senador en 1921 por el departamento del Tolima, siendo su suplente Enrique Olaya Herrera.

Ya retirado de toda actividad económica, política y social con el fin de dedicar los últimos años de su vida a los menesteres domésticos en su finca, falleció en Bogotá el 13 de octubre de 1935, a la edad de 78 años.

\section{Conclusiones}

En este ensayo se dio cuenta de la actividad empresarial que llevó a cabo el empresario Pedro Aquilino López Medina. Este hombre nacido en Bogotá y de extracción humilde, gracias a 
su tenacidad, su astucia y habilidad para los negocios, su capacidad para aprovechar las oportunidades que el entorno le brindó y al apoyo de miembros de la familia Samper Agudelo, sus relaciones con empresarios y banqueros nacionales y extranjeros, se convirtió en una de las figuras prominentes del empresariado del país descollando como exportador de café y gestor de proyectos relacionados con la actividad bancaria, manufacturera, los transportes y servicios públicos entre otros.

\section{Referencias}

Acosta, P. (2003). López Pumarejo. En marcha hacia su revolución. Bogotá: Universidad de Bogotá Jorge Tadeo Lozano.

Archivo General de la Nación (AGN). (1919). Notaría segunda, 08-01-1919.

Archivo General de la Nación (AGN). (1919). Notaría segunda, escritura 1.605, 27-08-1919.

Archivo General de la Nación (AGN). (1920). Notaría segunda, escritura 2.517, 01-12-1920.

Child, J. y Arango, M. (1988). Bancarrotas y crisis: 1842-1988. Bogotá: Grijalbo.

Dávila, C. (1986). El empresariado colombiano. Una perspectiva histórica. Bogotá: Pontificia Universidad Javeriana.

Edificio Pedro A. López: inicios del modernismo en la arquitectura colombiana. (2015). Disponible en: www.construdata.com/BancoMedios/.../metalica_14_legado_58a62.pdf.

Latorre, H. (1961). Mi novela. Apuntes autobiográficos de Alfonso López. Bogotá: Ediciones Mito.

López, A. (2009). Mis memorias. Bogotá: Editorial Oveja Negra.

Ocampo, J. (1984). Colombia y la economía mundial 1830-1910. Bogotá. Siglo XXI Editores - Fedesarrollo.

Ocampo, J. (1989). Los orígenes de la industria cafetera, 1830-1929. En A. Tirado: Nueva historia de Colombia (pp. 213-232). Bogotá: Planeta.

Randall, S. (2007). Alfonso López Michelsen, su vida, su época. Bogotá: Villegas Editores.

Zuleta, E. (1966). El presidente López. Medellín: Ediciones Albon. 